\title{
Radiant heat loss, an unexploited path for heat stress reduction in shaded cattle
}

\author{
A. Berman ${ }^{* 1}$ and T. Horovitz† \\ *Department of Animal Science, Faculty of Agriculture, Rehovot Campus, Hebrew University, Rehovot, 76100 Israel \\ †Department of Agricultural Meteorology, Meteorological Institute, Ministry of Transport, Bet Dagan 25, Israel
}

\begin{abstract}
Reducing thermal radiation on shaded animals reduces heat stress independently of other means of stress relief. Radiant heat exchange was estimated as a function of climate, shade structure, and animal density. Body surface portion exposed to radiant sources in shaded environments was determined by geometrical relations to determine angles of view of radiation sources (roof underside, sky, sun-exposed ground, shaded ground) on the animal's surface. The relative representation of environment radiation sources on the body surface was determined. Animal thermal radiation balance was derived from radiant heat gained from radiation sources (including surrounding animals) and that lost from the animal surface. The animal environment was assumed to have different shade dimensions and temperatures. These were summed to the radiant heat balance of the cow. The data formed served to estimate the effect of changes in intensity of radiation sources, roof and shaded surface dimensions, and animal density on radiant heat balance (Rbal) of cattle. Roof height effect was expressed by effect of roof temperature on Rbal. Roof underside temperature $\left(35\right.$ to $\left.75^{\circ} \mathrm{C}\right)$ effect on Rbal was reduced by roof height. If roof height were $4 \mathrm{~m}$, an increase in its underside temperature from 35 to $75^{\circ} \mathrm{C}$ would increase mean Rbal from -63 to $-2 \mathrm{~W} \cdot \mathrm{m}^{-2}$, whereas if roof height were $10 \mathrm{~m}$, Rbal would only increase from -99 to $-88 \mathrm{~W} \cdot \mathrm{m}^{-2}$. A hot ground temperature increase from 35 to $65^{\circ} \mathrm{C}$ reduced mean Rbal heat loss from -45 to $3 \mathrm{~W} \cdot \mathrm{m}^{-2}$. Increasing the surface of the shaded area had only a minor effect on Rbal and on the effect of hot ground on Rbal. Increasing shade roof height reduced the effect of roof temperature on Rbal to minor levels when height was $>8 \mathrm{~m}$. Increasing the roof height from 4 to $10 \mathrm{~m}$ decreased Rbal from -32 to $-94 \mathrm{~W} \cdot \mathrm{m}^{-2}$. Increasing indirect radiation from 100 to $500 \mathrm{~W} \cdot \mathrm{m}^{-2}$ was associated with an increase in Rbal from -135 to $+23 \mathrm{~W} \cdot \mathrm{m}^{-2}$. Their combined ef-
\end{abstract}

Received August 18, 2011

Accepted February 2, 2012.

${ }^{1}$ Corresponding author: berman@agri.huji.ac.il fects were lower Rbal with increasing roof height and a reduction in rate of decrease with increasing level of indirect radiation. Roof height as an Rbal attenuator declined with increasing indirect radiation level. The latter factor might be reduced by lowering roof surface radiation absorption and through roof heat transfer, as well as by use of shade structure elements to reduce indirect radiation in the shaded area. Radiant heat from the cow body surface may be reduced by lower cow density. Radiant heat attenuation may thus further elevate animal productivity in warm climates, with no associated operation costs.

Key words: radiant heat, heat stress abatement, shade, radiant heat balance

\section{INTRODUCTION}

Reducing the effect of heat stress on animal productivity in warmer climates emphasizes enhanced animal heat loss and reduction of heat gain from the environment. Environmental heat stress is most commonly estimated by the combined effects of air temperature and humidity (Dikmen and Hansen, 2009) and these are, accordingly, the main targets of heat stress relief. Air velocity and indirect thermal radiation intensity have received significantly less attention as heat stress factors.

Information is abundant on air temperature, air humidity, and air velocity because of the simplicity of their measurement. Radiant heat load, and in particular the indirect radiant heat load, is rather infrequently measured. Most available information on thermal radiation relates to the total radiation intensity. The radiant heat load incident on a sun-exposed dairy animal is about 3 times its metabolic heat production (da Silva et al., 2010). As the total heat dissipation capacity of a homeothermic animal is more or less constant, increased heat input from the environment reduces the potential for metabolic heat production (Walsberg and Wolf, 1995), thereby limiting the animal's productivity. Sheltering the animals from direct solar radiation by provision of shade leaves them exposed to indirect sky radiation and that emitted by the animal's surroundings. 
The first group of studies of radiant heat in animal shelters was likely that carried out on beef cattle shades in Death Valley in California (Kelly et al., 1950). It centered on the mean radiant intensity; that is, the average radiation intensity incident on an animal located in a given environment, as measured by the temperature of a black globe (Bedford and Warner, 1934). Such studies indicated that provision of shade might reduce radiant heat load by 30 to $60 \%$ (Ittner and Kelly, 1951).

Further studies using directional radiometers allowed the partition of the spherical thermal radiation into its components; namely thermal radiation coming from roof underside, sky, sun-exposed ground, and shaded ground (Bond et al., 1967). Large differences in radiation intensity were shown to prevail among these sources. The spherical radiant load incident on shaded animals might be reduced if the relative contributions of the various sources were known and shade may be modified to reduce the radiant heat load.

This report contains 2 phases: the representation of environment radiant energy sources on animal surface and the effects of shelter characteristics (i.e., shade height, shade size per cow, indirect and hot ground radiation, and the location of animal under the shade on that representation).

\section{MATERIALS AND METHODS}

\section{Representation of Environment Components on Animal Surface}

Thermal radiation heat from the environment impinges on the animal surface, from where it is absorbed into the body. The heat radiating from various sources in the environment is perceived by different parts of the body surface. Determining the relative impact of the various radiant components of the environment on the thermal balance requires an estimate of the surface of body upon which they radiate. The complexity of this thermal exchange requires a simplifying model. A cylindrical representation of the body was adopted in some studies of heat exchange (Clapperton et al., 1965; Wiersma and Nelson, 1967; Webb et al., 1986). In the present study, the body was viewed as a sagittal section of a cylinder, in which the body surface of the animal was represented by a circle. The elements of the surroundings were viewed as occupying various angles on the perimeter of the circle; that is, the surface of the animal. The angular representation of surrounding bodies on the surface of the body depends on the diameter of the animal, the dimension of the environment element, and the distance between the two. The angular representations were calculated for various dimensions of the surrounding elements and for various distances from the animal's body center.

The radiant environment surrounding an animal in the shade may be seen as consisting of the underside of the roof providing the shade, the cool shaded ground, the hot unshaded ground surrounding the shadow created by the shade, the indirect diffuse radiation from cool sky, and the radiation from the sun-exposed ground surrounding the shade (Figure 1). The effect of thermal radiation incoming from a part of the environment on the thermal radiation balance is relative to the portion of body surface facing that part of the environment and the intensity of the thermal radiation emitted by that part. The translation of incident radiation into heat absorbed in the body requires additional considerations (Gebremedhin et al., 1997) and was not included in this study, which focuses on the quantity of radiation incident on body surface.

The portion of body surface facing a particular component of the surroundings was expressed as the angle that contains the particular component. The cow was represented as a circle of $0.8 \mathrm{~m}$ mean diameter, of $1.4 \mathrm{~m}$ mean height with the abdomen at a height of $0.8 \mathrm{~m}$ and the center of the body assumed to be at $1.1 \mathrm{~m}$ above ground (McGovern and Bruce, 2000; ASAE, 2006). The center of the body of a standing cow was assumed at a fixed height above ground $(1.1 \mathrm{~m})$. The angle of view of the shaded area (Figure 1) was thus located with its center at $1.1 \mathrm{~m}$ above ground (a), and its linear dimension (b) represents the shaded area perceived by the body of the animal. The effect of the shaded area on the angle at which it is perceived on the surface of the body was examined by assuming the shaded area to vary by $1-\mathrm{m}^{2}$ steps between 4 and $20 \mathrm{~m}^{2}$ per cow, the

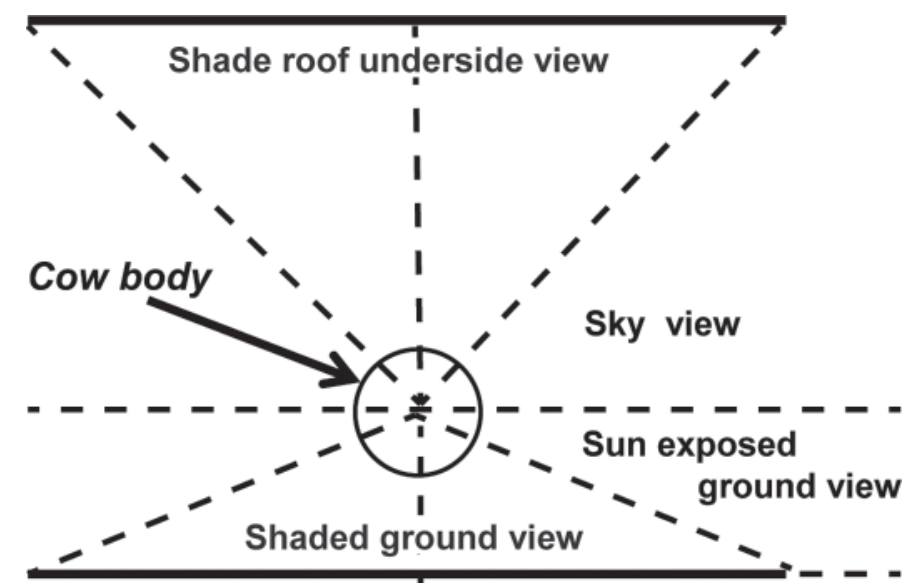

Figure 1. Schematic representation of the surrounding sources of indirect radiation impinging upon an animal kept under a shade. 
body center at $1.1 \mathrm{~m}$ above ground, the linear dimension of shade surface per cow (b), and the diagonal between the two (c). The angle was derived from the value $\mathrm{b} / \mathrm{c}$, the sine of the angle $<\mathrm{AC}$ multiplied by 57.3. The value of this angle was further multiplied by 2 to provide the full angle at which the shaded area is perceived by the animal body. The same approach was used to estimate the angle of perception of hot ground. The effects of shade size on the angle of view representing it and hot ground on the surface of the body were estimated by a generalized linear model (GLM) comprising second-order polynomial regressions.

The surface of the roof of the shade was practically identical to the surface of the shaded area. The angle of view of the roof underside and of the sky varies both with the size of the shade per cow $\left(b_{2}\right)$ and with the height $\left(\mathrm{a}_{2}\right)$ of the roof. The angle was derived as mentioned previously. To examine the relationship of angle size to shade structure dimensions, a data set was created in which roof size per cow (equal to shade per cow) was varied by 1-m steps from 3 to $20 \mathrm{~m}$ and height of roof was assumed as 4,8 , or $16 \mathrm{~m}$ per cow. The height of the roof relative to the animal was taken as the actual height minus the height of body center from the ground (i.e., $1.1 \mathrm{~m}$ ). The angles were calculated for roof heights of $4,6,8$, and $10 \mathrm{~m}$, and for shade surfaces of 4,8 , and $16 \mathrm{~m}^{2}$ per cow. The effects of roof height and shade size on the angle of view representing roof underside and cool sky on the body of a cow were estimated by a GLM model (SAS Institute, 1996) comprising second-order polynomial regressions.

\section{Relative Angles of View of Surrounding Components}

An animal located in a shed is exposed to 4 sources of thermal radiation: the underside of the roof, the sky, the hot ground, and the shaded ground in the shed, that add up to $360^{\circ}$. The angles of view of roof underside, sky, hot ground, and shaded ground are each differently affected by the size of roof (or shaded area) and by roof height. Their relative share in a circular view of the environment is represented by their relative angle. The relative angle in a circular environment is the angle of representation on body surface divided by 360 . The extent to which size of roof (or shaded area) affects the relative angle indicates the potential impact of shelter design on the representation of radiation sources on body surface. The relative share was calculated in the previously created data sets. The effect of shaded area (or roof size) and roof height was estimated by GLM regression, with relative angles of view of roof underside, sky, hot ground, and shaded ground as dependent class variables and surface area/cow and roof height and their interaction as independent variables.

\section{Contribution of Environment Components to Heat Balance}

In a following step, the relative contribution of shelter components to the radiant energy balance ( $\mathbf{R b a l}$ ) of a cow was evaluated. Global radiation intensity was assumed as that of midsummer midday data in the central coastal plain of Israel (Israel Meteorological Institute, Bet Dagan); namely, about $1,000 \mathrm{~W} \cdot \mathrm{m}^{-2}$. The indirect solar radiation was assumed to be 10,20, 30, and $50 \%$ of global solar radiation; that is, 100, 200, 300 , and $500 \mathrm{~W} \cdot \mathrm{m}^{-2}$, respectively. These values range from levels typical for a subtropical climate with clear skies (100 to $200 \mathrm{~W} \cdot \mathrm{m}^{-2}$ ), to slightly and moderately clouded skies $\left(300 \mathrm{~W} \cdot \mathrm{m}^{-2}\right)$, to more extreme conditions of haze $\left(500 \mathrm{~W} \cdot \mathrm{m}^{-2}\right)$ in which direct solar radiation is dispersed by particles carried by desert winds (http:// www.ims.gov.il). The radiant temperatures of radiation sources in the environment surrounding the shaded cow were assumed as follows: roof underside temperatures of $35,50,65$, and $75^{\circ} \mathrm{C}$; hot ground temperatures of 35 , 40,50 , and $65^{\circ} \mathrm{C}$; and shaded ground temperatures of 25 and $30^{\circ} \mathrm{C}$. Cow surface temperature was assumed to be $35^{\circ} \mathrm{C}$ (Berman, 2008) and air temperature $30^{\circ} \mathrm{C}$. These temperatures represent conditions of mild heat stress, a situation in which heat loss by radiation would be most relevant. Thermal radiation emanating emitted from cow surface, roof underside, shaded and hot ground surfaces, and cool sky were calculated by the Stefan-Boltzmann constant: $5.67 \times 10^{-8} \mathrm{~W} \cdot \mathrm{m}^{-2} \cdot \mathrm{K}^{-4}$, with a 0.95 emissivity coefficient. Radiant heat exchange occurs between surfaces of bodies viewing each other (Monteith, 1980). The Rbal was calculated as the difference between the radiant heat loss from the animal's surface and the radiant heat gain from the different components of the environment (i.e., roof underside, indirect radiation, unshaded ground, and shaded ground). Radiant heat loss from the animal surface depends on its temperature. Cow surface temperature is modified by several factors, including air temperature, metabolic rate, and air velocity. A change of $1^{\circ} \mathrm{C}$ in the surface temperature of the cow, calculated by the Stefan-Boltzmann equation, would modify Rbal by $6.5 \mathrm{~W} \cdot \mathrm{m}^{-2}$. A change of 1 to $2^{\circ} \mathrm{C}$ in main body surface temperature would thus have relatively small effects on radiant heat loss, yet it would imply significant changes in animal thermal state (Berman, 2004). Its effect would be additive; that is, to increase or decrease Rbal by 6.5 to $13 \mathrm{~W} \cdot \mathrm{m}^{-2}$, as it affects only the radiant heat loss and is without influence on the factors affecting the radiant heat from the environment and the relations between them.

The combinations of indirect solar radiation, roof underside temperatures, hot ground temperatures, and 
shaded ground temperatures created a data set of 128 records. The regression model consisted of Rbal as the dependent variable and roof height, shade surface, roof underside temperature, hot ground temperature, diffuse radiation, and their interactions as independent variables. These regression estimates were carried out for pooled indirect radiations of 10 to $500 \mathrm{~W} \cdot \mathrm{m}^{-2}$, as well as for individual indirect radiation levels of 100 , 200, 300, and $500 \mathrm{~W} \cdot \mathrm{m}^{-2}$.

\section{RESULTS}

\section{Angular Representation of Surrounding Elements}

As previously stated, the approach adopted here estimated a component in the surroundings perceived by the animal body as the angle by which it is represented on body surface as affected by shade structure characteristics. Effects that were not statistically significant are not listed in the regression equations.

\section{Shaded Ground Angle of View}

Increasing shaded ground surface per cow increased the angle of its representation on body surface, as estimated by the regression of the angle of view on shade size (Eq. [1]):

View angle $=65.3+5.8 \times S-0.14 \times \mathrm{S}^{2}\left(\mathrm{R}^{2}=0.99\right)$,

where $\mathrm{S}=$ shade surface area per cow $\left(\mathrm{m}^{2}\right)$.

Both regression coefficients were significant at $P<$ 0.01 . Increasing the size of the shaded area increased its representation on the body periphery. At the smaller shaded area per animal, $4 \mathrm{~m}^{2}$ of shade per animal, shade was represented on $86^{\circ}$ of body circumference, representing $24 \%(86 / 360)$. The angle presented by shaded ground on body surface increased from $4 \mathrm{~m}^{2}$ of shade per cow to about $14 \mathrm{~m}^{2}$ of shade per cow and stabilized at about $16 \mathrm{~m}^{2}$ shade per cow at an angle value of $123^{\circ}$. This angle represents $34 \%$ of total body circumference $(123 / 360)$.

\section{Roof Underside Angle of View}

Roof size per cow was equal to shaded area per cow. The angle of its representation on body surface depends not only on roof surface/cow but also on the height of the roof. The relationship between angle of view of roof underside, as seen from shade center, and roof height and roof surface per cow was estimated by the following second-order polynomial regression equation (Eq. [2]):
Roof view angle $=89.8-15.7 \times \mathrm{H}+0.65 \times \mathrm{H}^{2}$

$$
+2.3 \times \mathrm{S}-0.12 \times \mathrm{S} \times \mathrm{H}\left(\mathrm{R}^{2}=0.91\right),
$$

where $\mathrm{H}=$ roof height $(\mathrm{m})$.

The regression coefficients were all significant $(P<$ 0.01). Increasing the roof size increased the angle at which the roof underside was seen on body surface, whereas increasing the roof height had the opposite effect. Neither finding is novel. The quantitative relationship between them is important, however, in assessing the effect of shelter dimensions on the environment created under the roof. These relationships are depicted in Figure 2. When shade area per cow was 4 $\mathrm{m}^{2}$, increasing the roof height from 4 to $6 \mathrm{~m}$ reduced the angular representation of the shade shed by the roof on animal surface from $45^{\circ}$ to $26^{\circ}$, a $58 \%$ reduction in relative angle size. Increasing the shade size per cow increases the angle at which it is seen on the body surface, but this effect also depends on roof height. When roof height was $4 \mathrm{~m}$, increasing shade area from 4 to 12 $\mathrm{m}^{2}$ per cow increased roof representation on the animal body from $45^{\circ}$ to $60^{\circ}$, a factor of 1.3 (not a factor of 3 as might be intuited). For a roof height of $8 \mathrm{~m}$, increasing shade area from 4 to $12 \mathrm{~m}^{2}$ per cow would produce an almost 2 -fold increase in the angle representing it on the animal surface.

\section{Sky Angle of View}

The angle of view of the sky, as seen from shade center, was calculated as the difference between $90^{\circ}$ and the upper hemisphere angle of view divided by 2 . Its relationship to roof height and shade area per cow

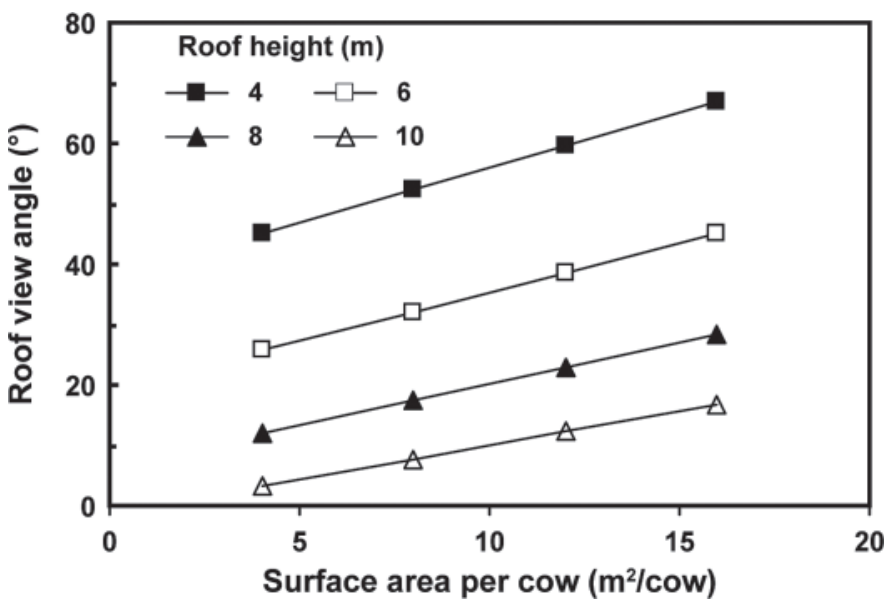

Figure 2. Relationship of shade roof angle of view to roof height $(\mathrm{m})$ and surface area per cow $\left(\mathrm{m}^{2} / \mathrm{cow}\right)$. The surface area per cow is identical to shade roof size per cow. 
was estimated by a second-order polynomial regression equation (Eq. [3]):

$$
\begin{aligned}
\text { Sky angle } & =90.2+17.1 \times \mathrm{H}-0.66 \times \mathrm{H}^{2}-2.3 \times \mathrm{S} \\
& +0.12 \times \mathrm{H} \times \mathrm{S}\left(\mathrm{R}^{2}=0.91\right) .
\end{aligned}
$$

The angle of view of the sky declined with increasing shade area per cow and increased with increasing roof height. The rate of decrease was similar at various roof heights. The effect of roof height was slightly greater with increasing shade size; for example, at 4 $\mathrm{m}^{2}$ of shade per cow, increasing the roof height from 4 to $8 \mathrm{~m}$ increased the angle of view of the sky by $22 \%$, whereas at $16 \mathrm{~m}^{2}$ per cow, the percentage increase was $29 \%$. This indicates that increasing the shade surface per cow only moderately reduced the sky angle of view, and successive increments in roof height had smaller effects on sky angle of view.

\section{Cool Sky View from Shade Side}

The angle of view of the sky is affected by the distance between body center and edge of the shed; that is, the location of the cow. If cows are allotted $0.85 \mathrm{~m}$ at the manger, and $20 \mathrm{~m}^{2}$ of shade are allotted per cow, the width of the shed would be $23.5 \mathrm{~m}$. A cow might locate itself at variable distance (D) from shed side and hence be exposed to a variable angle of the sky (Eq. $[4])$ :

$$
\begin{gathered}
\text { Cool sky angle }=60-12.4 \times \mathrm{D}+0.47 \times \mathrm{D}^{2} \\
+7.1 \times \mathrm{H}-0.3 \times \mathrm{H}^{2}\left(\mathrm{R}^{2}=0.98\right) .
\end{gathered}
$$

Both distance from the side of the shed and height of the roof have marked effects on the perception of cool sky by the cow (Figure 3). If roof height is $10 \mathrm{~m}$, cool sky angle is $87^{\circ}$ for an animal standing $1 \mathrm{~m}$ from the roof edge and declines to $53^{\circ}$ for an animal $8 \mathrm{~m}$ from the roof edge, a $40 \%$ decline. If roof height is $4 \mathrm{~m}$, the respective angles of cool sky become $72^{\circ}$ and $25^{\circ}$, a $65 \%$ decline. The relative reduction in cool sky exposure angle with distance from the edge is thus markedly greater when roof height is less.

\section{Relative Angles of Radiation Sources}

The relative presentation of the shaded area on body surface was only moderately affected by shaded area size: it increased from 24 to $34 \%$ when the shaded area increased from 4 to $16 \mathrm{~m}^{2} / \mathrm{cow}$. A similar effect was evident for the relative hot ground presentation. It was only moderately modified by shaded area surface: it decreased from 26 to $16 \%$ with surface area of shade increasing from 4 to $16 \mathrm{~m}^{2} / \mathrm{cow}$. On the other hand, relative roof and sky angle were affected by both roof height and surface area. In both cases, the effect of roof height was dominant (85\% of total variance) with a minor effect of surface area. Increasing roof height from 4 to $10 \mathrm{~m}$ increased sky view from 30 to $39 \%$, whereas increasing shade surface area from 4 to $16 \mathrm{~m}^{2} /$ cow reduced sky view from 42 to $36 \%$. Similarly, roof view was mostly affected by roof height: it decreased from 19 to $4 \%$ with roof height increasing from 4 to 10 $\mathrm{m}$, whereas increasing shade surface area from 4 to 16 $\mathrm{m}^{2} /$ cow increased relative roof view from 8 to $13 \%$.

\section{Effect of Shed Dimensions on Rbal}

The heat balance Rbal was estimated by the difference between the radiant heat gained and that lost. The radiant heat in a shaded environment originates exclusively from the indirect radiation. The intensity of the latter is characteristic for given climates. The data of different radiation intensity levels were therefore analyzed separately by both categorical and linear analysis regression models. The Rbal data were analyzed for effects of shaded area per cow, roof underside temperature, shaded ground temperatures, and hot ground temperatures. The model accounted for 0.94 to 0.98 of total variation.

The mean $\mathrm{Rbal}$ varied from a negative heat balance of $-134 \pm 1$ at $100 \mathrm{~W} \cdot \mathrm{m}^{-2}$ indirect radiation to a positive heat balance of $23 \pm 1 \mathrm{~W} \cdot \mathrm{m}^{-2}$ at $500 \mathrm{~W} \cdot \mathrm{m}^{-2}$ indirect radiation. Surface area per cow had a very minor main effect on Rbal, $<2 \%$ of Rbal variation, at all indirect radiation levels. The contribution of the other indepen-

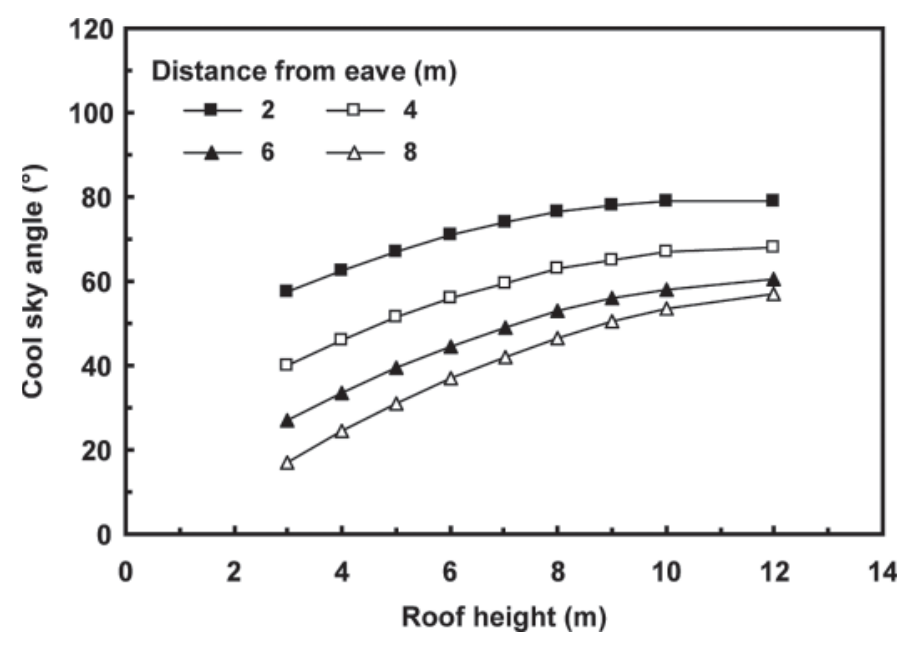

Figure 3. Relationship of distance from shade eave $(\mathrm{m})$ to angle of view of sky (degrees). 
dent factors in the model to the variation in Rbal was dependent on the indirect radiation level. It was similar at 100 and $200 \mathrm{~W} \cdot \mathrm{m}^{-2}$ of indirect radiation: roof height, hot ground temperature, and roof underside temperature accounted for 0.5 to $0.6,0.2$ to 0.3 , and 0.09 to 0.11 of total variation, respectively. Their contribution was different at $500 \mathrm{~W} \cdot \mathrm{m}^{-2}$ indirect radiation: hot ground temperature, roof underside temperature, and roof height accounted for $0.5,0.22$, and 0.14 of variation, respectively; that is, roof height contribution was markedly reduced at the higher indirect radiation. At $300 \mathrm{~W} \cdot \mathrm{m}^{-2}$ indirect radiation, an intermediate contribution order was apparent: roof height and hot ground temperature had similar contributions to variation, 0.4 and 0.35 , respectively, with roof underside temperature maintaining a contribution similar to that at the other indirect radiation levels (0.14).

Additional information on the effect of indirect radiation may be found in the coefficients of the linear regressions carried out at the different levels of indirect radiation. The effects of roof underside temperature and hot ground temperature on Rbal, as estimated by the magnitude of the linear regression coefficients, were independent of indirect radiation. The coefficients were identical in all regressions: 2.27 and $1.62 \mathrm{~W} \cdot \mathrm{m}^{-2} \cdot{ }^{\circ} \mathrm{C}^{-1}$, respectively. In contrast, the roof height effect and the intercepts of the regressions were highly dependent upon the level of indirect radiation. The effect of roof height on mean Rbal changed from -3.2 to $-0.7,1.8$, and $6.9 \mathrm{~W} \cdot \mathrm{m}^{-2} \cdot \mathrm{m}^{-1}$ roof height with indirect radiation increasing from $100 \mathrm{~W} \cdot \mathrm{m}^{-2}$ to 200,300 , and $500 \mathrm{~W} \cdot \mathrm{m}^{-2}$, respectively. In parallel, the intercept value changed from -135 to $-113,-91$, and $-48 \mathrm{~W} \cdot \mathrm{m}^{-2}$ when indirect radiation increased.

On average, increasing the roof height from 4 to 10 $\mathrm{m}$ decreased Rbal from -32 to $-94 \mathrm{~W} \cdot \mathrm{m}^{-2}$. Increasing indirect radiation had an opposite effect: its increase from 100 to $500 \mathrm{~W} \cdot \mathrm{m}^{-2}$ was associated with an increase in Rbal from -135 to $+23 \mathrm{~W} \cdot \mathrm{m}^{-2}$. Their combined effects on Rbal (Figure 4) indicate that Rbal generally declines with increasing roof height, and that the rate of decrease is reduced with increasing level of indirect radiation. Increasing roof height increases sky angle of view, and the sky angle of view effect on Rbal would be proportional to the intensity of the indirect radiation. The interaction between variable exposure to sky and to indirect radiation intensity are reflected in the decline of Rbal with increasing roof height, the increase in Rbal level with increasing indirect radiation, and finally in the attenuation of the roof height effects at the higher indirect radiation level. These strongly suggest that the effect of roof height on Rbal as an attenuator of Rbal declines with increasing level of indirect radiation.

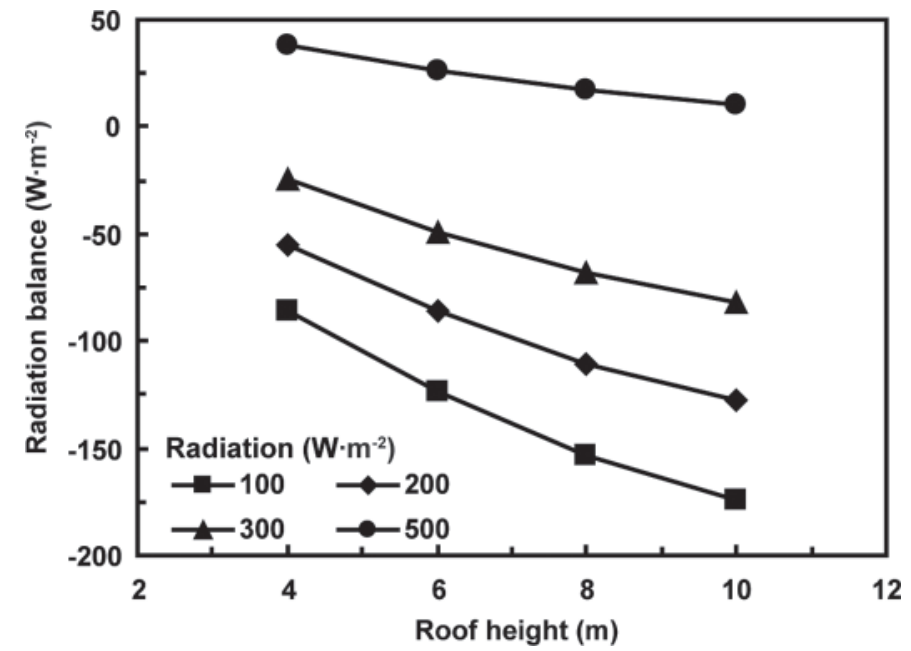

Figure 4. Relationship of animal radiation balance $\left(\mathrm{W} \cdot \mathrm{m}^{-2}\right)$ to indirect radiation intensity $\left(100,200,300\right.$, or $\left.500 \mathrm{~W} \cdot \mathrm{m}^{-2}\right)$ and roof height $(\mathrm{m})$.

An additional effect of roof height is expressed in its impact on the effect of roof temperature on Rbal. The effect of roof underside temperature on Rbal was examined for its relation to roof height and roof underside temperature (Figure 5). The overall effect of roof height was to markedly reduce the effect of the roof underside temperature on Rbal. At a 4-m roof height, an increase in roof underside temperature from 35 to $75^{\circ} \mathrm{C}$ was accompanied by a marked deterioration in Rbal, which increased from -63 to $-2 \mathrm{~W} \cdot \mathrm{m}^{-2}$. In contrast, at a 10-m roof height, the temperature of roof underside only had small effect on Rbal, an increase from -99 to $-88 \mathrm{~W} \cdot \mathrm{m}^{-2}$.

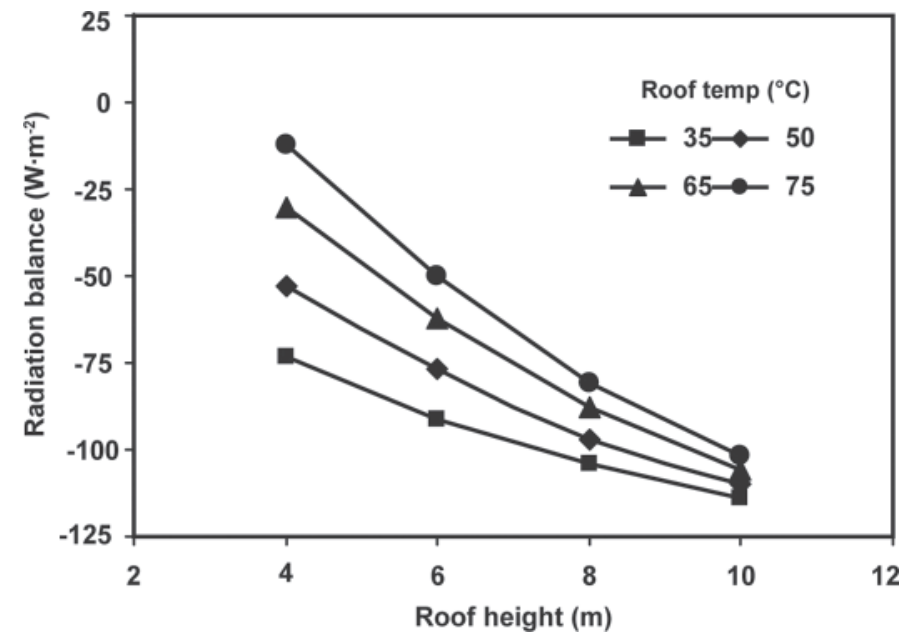

Figure 5. Relationship of animal radiant energy balance $\left(\mathrm{W} \cdot \mathrm{m}^{-2}\right)$ to roof underside temperature $\left(35,50,65\right.$, or $\left.75^{\circ} \mathrm{C}\right)$ and roof height (m). 
As mentioned above, the effect of ground temperature was examined in this model as independent of environmental radiation. In this model, global radiation was constant, only indirect radiation intensity was varied, and it may be presumed that indirect radiation was only weakly related to indirect radiation. Ground temperature was presumed a constant effect, additive to the other factors, unlike the real-life situation. The mean effect of hot ground temperature increase from 35 to $65^{\circ} \mathrm{C}$ was to reduce animal radiant heat loss from -45 to $3 \mathrm{~W} \cdot \mathrm{m}^{-2}$. The mean effects of increasing hot ground temperature (from 35 to $65^{\circ} \mathrm{C}$ ) and roof underside temperature (from 35 to $75^{\circ} \mathrm{C}$ ) were similar in their magnitude, 49 and $36 \mathrm{~W} \cdot \mathrm{m}^{-2}$. The size of the shaded area had a negligible effect on Rbal when indirect radiation was $100 \mathrm{~W} \cdot \mathrm{m}^{-2}$ of total: it varied from 21 to 23 $\mathrm{W} \cdot \mathrm{m}^{-2}$.

\section{View Angle of Neighboring Cows}

The bodies of cows are sources of thermal radiation additional to those of the inanimate environment. A cow would thus view other cows, and in the space between them, it would view elements of the surroundings. Cows, in contrast to the other environment components, do not a have a fixed location in the environment, neither are they similarly oriented. An assessment of radiation interchange between cows thus requires a spatial representation of the cow's body as well as of the environment perceived by it.

Cows with BW of $600 \mathrm{~kg}$ are about $1.5 \mathrm{~m}$ high (Brody, 1945). The cows are therefore located within a 1.5-m-high layer at variable distances between each other. The mean distance between cows varies with the space allotted per cow, which varies from 3 to $20 \mathrm{~m}^{2}$ per cow in different farming systems.

In terms of radiation exchange, cows present to neighboring cows as 2-dimensional bodies. Cows may present side, back, or front views to other cows, the latter 2 views being largely similar. The side view of a 600-kg dairy cow may be represented by a cylinder having a surface area of $6.54 \mathrm{~m}^{2}, 0.73 \mathrm{~m}$ in diameter, a length of $2.48 \mathrm{~m}$, with its center located at $1.1 \mathrm{~m}$ above ground (McGovern and Bruce, 2000). Seen as a radiating body, it is equivalent to a $2.48 \times 0.73 \mathrm{~m}$ rectangle of $1.81 \mathrm{~m}^{2}$ surface, approximated by adjacent circles of $1.52 \mathrm{~m}$ diameter with center at $1.1 \mathrm{~m}$ above ground. The rear view is approximated by a $0.8 \times 0.5$ $\mathrm{m}$ rectangle (ASAE, 2006); that is, a $0.4-\mathrm{m}^{2}$ surface, equivalent to circles of $0.72 \mathrm{~m}$ in diameter. A simplifying approach may be adopted in which half the cows present a side view and the other half a rear view. By this approach, cows would be represented by circles of $1.12 \mathrm{~m}$ diameter, the mean of 1.52 and $0.73 \mathrm{~m}$.
The angle of view of the circles varies with distance between cow body centers. A maximal cow density would occur when their bodies touch each other. The angle of view of a neighboring cow is expressed by the sine of an angle, in which $a$ is the distance between the 2 cow centers, $b$ is the radius of the cow view $(0.56 \mathrm{~m})$, and $c$ is the line connecting the body center of the first cow with the body periphery of the second cow. The angle of view of a body was calculated by multiplying by 2 the value obtained for the radius of the body. The change of the angle of view with distance (d) between 2 cows was calculated for circles of 1.52, 1.12, and 0.72 m diameter (Eq. [5] to [7]):

$$
\begin{gathered}
0.73 \text {-m diameter }=76.3-41.3 \times \mathrm{d} \\
+8.14 \times \mathrm{d}^{2}-0.53 \times \mathrm{d}^{3}, \\
1.12 \text {-m diameter }=76.3-26.7 \times \mathrm{d} \\
+3.46 \times \mathrm{d}^{2}-0.15 \times \mathrm{d}^{3}, \\
1.52 \text { - } \mathrm{m} \text { diameter }=76.3-19.7 \times \mathrm{d} \\
+1.88 \times \mathrm{d}^{2}-0.06 \times \mathrm{d}^{3} .
\end{gathered}
$$

The $\mathrm{R}^{2}$ coefficients of the regressions were 0.98 . The coefficients for the 1.12-m-diameter body were similar to those for the 1.52-m-diameter body. The representation angles decrease with increasing distance between body centers. At $2 \mathrm{~m}$ distance, the rear side view presented a $22^{\circ}$ angle and the side view presented a $44^{\circ}$ angle. At $4 \mathrm{~m}$ distance, these angles decreased to $8^{\circ}$ and $24^{\circ}$, respectively. The presentation angle of a rear body view remained more or less stable at distances beyond $4 \mathrm{~m}$, whereas that of a body side declined to $<10^{\circ}$ at distances $>6 \mathrm{~m}$.

The radiant exchange between cows is contained within a $1.5-\mathrm{m}$ layer above ground within which cows live. A cow may be surrounded by 15 cows within a $6-\mathrm{m}$ distance, assuming that 10 cows present a side view and 5 cows a front view (Figure 6). Such a situation represents a surface of $7.5 \mathrm{~m}^{2} / \mathrm{cow}$. Clearly, this distribution of cows in a shed is not omnipresent, nor is it unique. The number of cows perceived by a given cow would be affected by the relative proportions of cows presenting a side view and those presenting a front view. Assuming that all cows present either a side or a front view would change the number of cows occupying the whole horizontal layer from 13 to 27 . These indicate that the surface area/cow at which the reference cow perceives only cow bodies would range between 4.2 and $8.7 \mathrm{~m}^{2} /$ cow, depending on the orientation of cow bodies relative to the reference cow. Allocating a greater surface per cow would allow the cows to "see" 
and exchange thermal radiation with other elements of the environment located within the 1.5-m layer. We assumed that in warm shaded environments, the body surface temperature of the cow is about $35^{\circ} \mathrm{C}$. If surface temperature were similar in all cows, the net radiant heat exchange between them would be small to nil. The bodies of cows would, however, replace other environment components found in the lower stratum of the environment, namely shaded and unshaded ground. The temperature of unshaded ground is about $45^{\circ} \mathrm{C}$ (range 35 to $55^{\circ} \mathrm{C}$ ) and that of shaded ground about $30^{\circ} \mathrm{C}$. If we assume that these two contribute equally to the thermal radiant exchange, their average temperature, namely $37.5^{\circ} \mathrm{C}$, may represent the mean temperature of the 1.5-m-high layer surrounding the cows. The difference in radiant temperature between 37.5 and $35^{\circ} \mathrm{C}$ (the surface temperature of cows) implies a tentative $16 \mathrm{~W} \cdot \mathrm{m}^{-2}$ additional radiant heat loss from an approximately $30^{\circ}$ angle of the body periphery of the reference cow. This angle represents about $8 \%$ of body surface.

\section{DISCUSSION}

The thermal radiation load on maintenance of stable body temperature has long been recognized as a main factor limiting cattle productivity, as a stressor in addition to air temperature and humidity. A spherical view of incoming thermal radiation was first conceived with the development of the black globe thermometer (Bedford and Warner, 1934) and was further applied to shades for beef cattle (Kelly et al., 1950).

The spherical thermal radiation approach had been used to reduce thermal radiation under shades by selective use of roofing materials and shade design (Bucklin et al., 1993; Eigenberg et al., 2010). Higher shades (12 $\mathrm{ft}$ ) were stated to reduce radiant heat more than low shades (6 ft), attributed to a greater exposure to the cool sky (Kelly et al., 1950). Providing cattle with shade did not produce consistent results in various studies (Buffington et al., 1983), which might be related to shade material or shade design. It is significant that behavioral thermoregulation was not sensitive enough in dairy cattle to induce preference between a $500 \mathrm{~W} \cdot \mathrm{m}^{-2}$ and a $99 \%$ shade cloth simultaneously offered at air temperatures ranging from 8 to $29^{\circ} \mathrm{C}$ in Holstein cows producing about $30 \mathrm{~kg}$ of milk/d (Schutz et al., 2009).

The impact of shade structure characteristics on the underlying conditions has generally been examined by using black globe thermometers (Bond and Kelly, 1955). The separate effects of solar (Porter et al., 1986) and ground thermal radiation on the thermal radiation impact on animal thermal balance have been assessed by directional radiometers (Bond et al., 1967). Solar- imeters attached to a rotating cylinder simulating a sheep were used to measure total hemispherical radiation profile at $45^{\circ}$ intervals at solar altitudes from 0 to $90^{\circ}$ (Clapperton et al., 1965). In the wildebeest, the frequency of the orientation of the animal parallel to incident radiation increased with rising ambient temperature and solar radiation intensity. Such orientation was calculated to reduce radiant heat absorbed by 300 $\mathrm{W} \cdot \mathrm{m}^{-2}$ (Maloney et al., 2005). Large differences in the intensity of thermal radiation flux from various elements in the animal environment have been shown by directional radiometers (Bond et al., 1967). These have not, however, been integrated into an overall balance of radiant heat. The potential of alleviating heat stress by selective exposure of animals to specific environment elements was explored in this study. For this, knowledge of the relative contribution of environment elements to the thermal balance is required.

A main contribution of this study lies in the approach developed for estimating the relative contribution of environmental radiation sources to the radiation input on the animal. The body animal was viewed as a sagittal

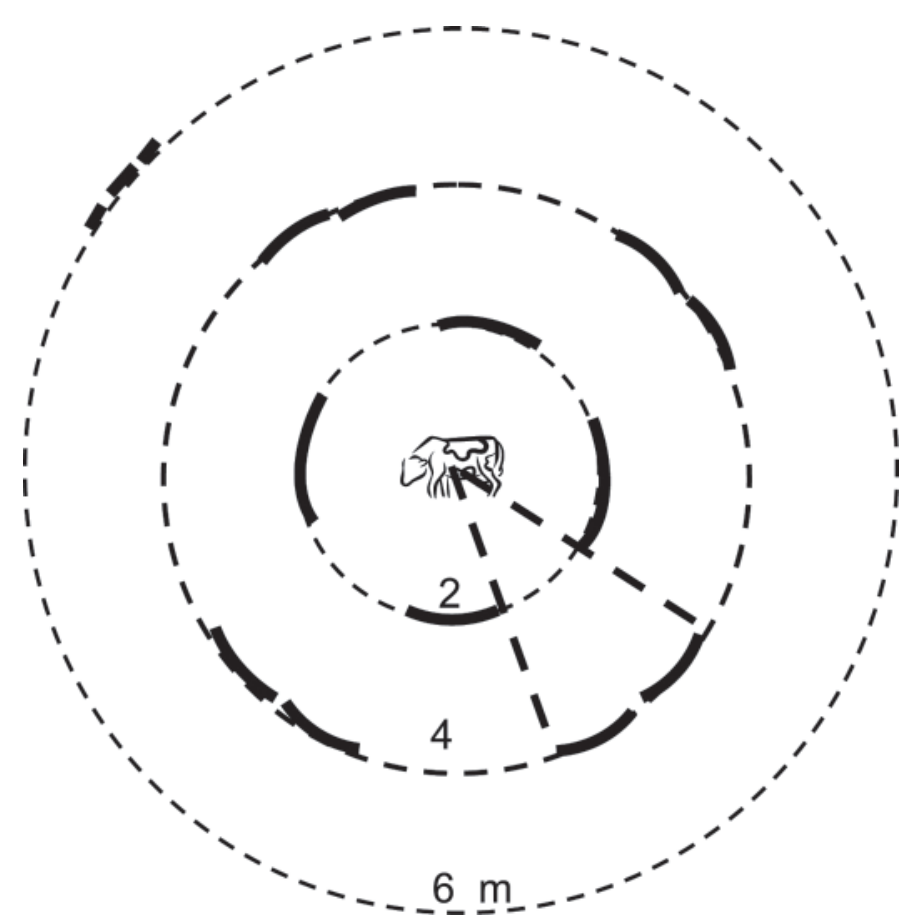

Figure 6. A schematic diagram of cows as viewed from the center of the body of a reference cow. The cows are viewed in the spaces between other cows' bodies. The angle of view of a body decreases with increasing distance from the body center of the reference cow and is lower for the cows presenting a rear (or front) view than for those presenting a side view. The diagram represents 2 side and 2 rear views at $2 \mathrm{~m}$ distance from reference cow, 10 side views of cows at $4 \mathrm{~m}$ distance, and 3 rear views of cows at $6 \mathrm{~m}$ distance. These fill all the $360^{\circ}$ perceived by the reference cows. 
section of a cylinder, represented by a circle. A cylindrical representation of the animal body has been used in studies of heat exchange (Clapperton et al., 1965; Wiersma and Nelson, 1967; Webb et al., 1986). Radiation sources in the environment are here represented by their angle of view from body center. A similar, but not identical, geometrical approach was used in estimating thermal radiation incident on a human body in an urban environment (Matzarakis et al., 2010) and in estimating earth-emitted radiation with radiometers located on satellites (Weaver and Green, 1980). The angular representation of surrounding bodies on the surface of an animal is independent of animal size; their absolute surface on body periphery depends on animal diameter, and the relative space they occupy on body periphery depends on the dimension of the surrounding body and the distance between the two. The angular representation approach permitted the calculation of the animal body surface reached by incoming thermal radiation from various elements of the environment.

Another contribution of this study lies in the analysis of the effects of shade structure components on the angular representation of environmental radiation. The effects of shade structure dimensions on the angles of view of individual shaded environment components were determined by polynomial equations. Subsequently, the relative representation of environment components on body periphery was estimated as a function shade structure dimensions. The equations developed in this study may be used to estimate the relative body surface reached by radiation sources in a variety of animal shelters.

Increasing shade area might be an effective means to improve heat balance of animals by allowing them to lose more heat by radiation to a surface cooler than their body surface. In the United States, recommended shaded floor space varies from 1.4 to $2.5 \mathrm{~m}^{2}$ per cow (Hahn, 1985) to 4.2 to $5.6 \mathrm{~m}^{2}$ per cow (Buffington et al., 1983). In Australia, $3.3 \mathrm{~m}^{2}$ shade per steer is provided (Gaughan et al., 2010), and in the United Kingdom, space allowances of 6.7 to $13.5 \mathrm{~m}^{2}$ are used (Fregonesi and Leaver, 2002). Increasing space allowance per cow from 7 to $14 \mathrm{~m}^{2}$ in loose housing reduces aggression and increases lying/standing patterns but not milk yield (Metz et al., 1981). Larger shade space is used in loose housing in Israel, ranging from 16 to $20 \mathrm{~m}^{2}$ per cow. The present study suggests that shaded area per cow, as an independent factor, has a limited effect on the relative portion of body surface exposed to shade and therefore is not likely to have a marked effect on reducing the radiant heat load on animals kept in shaded environments.

The relative representations of the shaded area (shaded area is identical to roof area) and hot ground were only moderately affected by increasing the shaded area from 4 to $16 \mathrm{~m}^{2} / \mathrm{cow}$. Such increases in surface area increased the relative shaded area representation on body surface from 24 to $34 \%$ and reduced relative hot ground representation from 26 to $16 \%$ of body surface. The effect of increasing roof height was markedly greater than that of increasing the shaded surface. The relative roof representation on body surface was strongly affected by roof height: increasing it from 4 to $10 \mathrm{~m}$ reduced its relative representation from 19 to $4 \%$. Increasing surface area from 4 to $16 \mathrm{~m}^{2} /$ cow increased relative roof view from 8 to $13 \%$. The opposing effects of such concurrent increases in roof height and surface area thus counteract each other, so that a concomitant increase in both of them leaves relative roof representation unaltered. Similar counterbalancing effects are true for roof height and surface area effects on sky relative angle. These effects are, however, independent of climate factors such as temperature and indirect radiation intensity.

The additional contribution of this study is the translation of the above relationships into a thermal radiation balance in the difference between radiant heat gained and that lost. Subsequently, the effects of environmental indirect radiation and of shade structure elements on radiation balance were estimated. The Rbal was predominantly affected by the flux of indirect radiation flux from the sky. It varied from a mean value of $-134 \mathrm{~W} \cdot \mathrm{m}^{-2}$ when indirect radiation was 100 $\mathrm{W} \cdot \mathrm{m}^{-2}$, to $23 \mathrm{~W} \cdot \mathrm{m}^{-2}$ when indirect radiation was 500 $\mathrm{W} \cdot \mathrm{m}^{-2}$, for a cow standing isolated with no radiation input from bodies of neighboring cows.

If the presence of surrounding cows is included so that they replace the shaded surface and the hot ground radiation, the Rbal may vary from -65 , to -26 , 13 , and $92 \mathrm{~W} \cdot \mathrm{m}^{-2}$, for indirect radiation levels of 100 , 200,300 , and $500 \mathrm{~W} \cdot \mathrm{m}^{-2}$, respectively. In this study, a surface temperature of $35^{\circ} \mathrm{C}$ was assumed (Berman, 2008), appropriate for a high-producing cow at $30^{\circ} \mathrm{C}$. Lower surface temperatures would increase Rbal by 6.5 $\mathrm{W} \cdot \mathrm{m}^{-2}$ per $1^{\circ} \mathrm{C}$ reduction, with opposite changes for higher surface temperatures. These values should be viewed in relation to the $173 \mathrm{~W} \cdot \mathrm{m}^{-2}$ metabolic heat production of a cow yielding $35 \mathrm{~kg} / \mathrm{d}$ (NRC, 2001).

These gross estimates suggest a potential role for indirect radiation in the thermal balance of dairy cattle. Enhanced radiant heat loss to large, cool, wet pads may be partly responsible for the improved thermal balance of animals in evaporative tunnel cooling systems (Smith et al., 2006). This effect is not apparent in the commonly used temperature-humidity index, neither is it immediately obvious from black globe measurements. These values point to the large potential improvements attainable in animal sheds by adequate modifications 
to reduce indirect radiation intensity. This path of heat exchange is independent of air temperature changes induced by evaporative cooling (Ryan et al., 1992) or of convective heat loss changes induced by forced ventilation and wetting (Flamenbaum et al., 1986).

The shed structure quality in this respect depends upon prevailing indirect radiation. In an environment with indirect radiation of $100 \mathrm{~W} \cdot \mathrm{m}^{-2}$, increasing shade height from 4 to $10 \mathrm{~m}$ would improve Rbal from -86 to $-174 \mathrm{~W} \cdot \mathrm{m}^{-2}$. This increase in radiant heat loss could compensate for high ambient temperature and humidity stresses. Hot ground temperature is expected to have a significant effect, albeit smaller than that of roof height. At the other extreme, at $500 \mathrm{~W} \cdot \mathrm{m}^{-2}$ of indirect radiation, the same increase in roof height would have little effect on Rbal, so that it would be only slightly reduced by increasing roof height and its effect would be dependent on shade underside temperature.

Taken as a whole, this study underlines that shade height would have a dominant effect of Rbal, and that the effect would depend on indirect radiation level: at low indirect radiation (10 to $200 \mathrm{~W} \cdot \mathrm{m}^{-2}$ ), increasing shade height would markedly reduce Rbal, whereas at higher indirect radiation $\left(500 \mathrm{~W} \cdot \mathrm{m}^{-2}\right)$, increasing it would increase the Rbal. Roof underside temperature effect on Rbal strongly depends upon roof height: at 4 $\mathrm{m}$ height, it would have a marked effect, which would decline to a negligible value when roof height approaches $10 \mathrm{~m}$. This also implies that increasing roof height may reduce the need for selective coating of the upper roof surface to reduce solar radiation absorption. Indirect radiation variation may be involved in the inconsistent effects of providing shade (Buffington et al., 1983). These imply that a higher shade improves Rbal when indirect radiation is within 10 to $200 \mathrm{~W} \cdot \mathrm{m}^{-2}$, whereas, when high indirect radiation prevails, Rbal is improved by reducing shade underside temperature by reducing solar radiation absorption and heat transfer to roof underside. In the intermediate indirect radiation levels, unconventional shade elements may be used to reduce the effect of indirect radiation on the radiant heat load in the shaded environment and allow the use of higher shades for reduction of shade roof temperature effects.

Additional, previously neglected elements brought up in this study are the estimate of heat radiation emanating from the bodies of cows as a function of animal density and the effect of the location of the animal relative to shelter edge on its exposure to sky radiation. Both elements may be used to reduce the intensity of the thermal radiation to which animals are exposed in both loose housing and freestall systems.

The value of changes for the Rbal of cattle may be inferred from the relationships between Rbal and ambi- ent temperature. For this purpose, a thermal balance model (McGovern and Bruce, 2000) adapted to suit Holstein cattle in warm climates (Berman, 2005) was used to estimate radiant heat loss at ambient temperatures ranging from 25 to $45^{\circ} \mathrm{C}$ while mean radiant temperature of the environment was kept constant at $30^{\circ} \mathrm{C}$. This indicated that in terms of thermal balance, a $3.7-\mathrm{W} \cdot \mathrm{m}^{-2}$ increase in animal radiant heat loss is equivalent to a $1^{\circ} \mathrm{C}$ reduction in ambient temperature. Such relationship points to the thermal balance value of indirect radiation changes that may be attained by shade structure modifications. But, it also strongly suggests that some of the smaller changes in Rbal produced by relatively slight modifications in shed characteristics may have significant effects on the thermal balance of the animals in the shaded environment.

Perhaps the most important element brought up in this study is that the shelter characteristics required for reducing indirect radiation depend on the intensity of the prevailing sky radiation. Its impact may be attenuated by use of panels at the shed sides, so that high roof benefits may be attained, even in climates with higher indirect radiation. Another important element, relating to heat stress relief, is that radiant heat attenuation is independent of air temperature and humidity. As such, it is a means for heat stress relief, the effects of which are additive to those of evaporative cooling, forced ventilation, and the combination thereof. Radiant heat attenuation may thus further elevate the threshold of animal productivity in warm climates.

\section{CONCLUSIONS}

Heat stress in shaded animals may be significantly attenuated by the reduction of radiant heat incident on the animals and reinforcement of radiant heat loss from the animals. Incident radiation depends on the climatedetermined indirect radiation intensity, housing characteristics, and animal density. At low indirect radiation levels, incident radiation is mostly due to thermal radiation incoming from a hot roof and is reduced by increasing roof height, which also increases radiant heat loss from body surface to the sky. At moderate to high indirect radiation, the effect of increasing roof height is counterbalanced by the increase in incoming indirect radiation. The latter may be attenuated by panels on shed sides. Radiation emitted from the body surface of cows is absorbed by the body surface of surrounding cows. Cow bodies restrict radiant heat exchange with shaded area and hot ground. Increasing the shaded surface per cow has a small effect on thermal balance because of the relatively small body surface exposed to shaded ground. 


\section{REFERENCES}

ASAE. 2006. Dimensions of Livestock and Poultry. ASAE D321.2 MAR1985 (R2006). Am. Soc. Agric. Eng., St. Joseph, MI.

Bedford, T., and C. Warner. 1934. The globe thermometer in studies of heating and ventilation. J. Hyg. (Lond.) 34:458-473.

Berman, A. 2004. Tissue and external insulation estimates and their effects on prediction of energy requirements and of heat stress. J. Dairy Sci. 87:1400-1412.

Berman, A. 2005. Estimates of heat stress relief needs for Holstein dairy cows. J. Anim. Sci. 83:1377-1384.

Berman, A. 2008. Increasing heat stress relief produced by coupled coat wetting and forced ventilation. J. Dairy Sci. 91:4571-4578.

Bond, T. E., and C. F. Kelly. 1955. The globe thermometer in agricultural research. Agric. Eng. 36:251-255.

Bond, T. E., C. F. Kelly, S. R. Morrison, and N. Pereira. 1967. Solar, atmospheric, and terrestrial radiation received by shaded and unshaded animals. Trans. ASAE 10:622-627.

Brody, S. 1945. Bioenergetics and Growth with Special Reference to the Energetic Efficiency Complex in Domestic Animals. Reinhold Publ., New York, NY.

Bucklin, R. A., R. W. Bottcher, G. L. v. Wicklen, and M. Czarick. 1993. Reflective roof coatings for heat stress relief in livestock and poultry housing. Appl. Eng. Agric. 9:123-129.

Buffington, D. E., R. J. Collier, and G. H. Canton. 1983. Shade management systems to reduce heat stress for cows in hot humid climates. Trans. ASAE 26:1798-1802.

Clapperton, J. L., J. P. Joyce, and K. L. Blaxter. 1965. Estimates of the contribution of solar radiation to the thermal exchanges of sheep at a latitude of $55^{\circ} \mathrm{N}$. J. Agric. Sci. (Camb.) 64:37-49.

da Silva, R. G., M. M. Guilhermino, and D. A. F. de Morais. 2010 Thermal radiation absorbed by dairy cows in pasture. Int. J. Biometeorol. 54:5-11.

Dikmen, S., and P. J. Hansen. 2009. Is the temperature-humidity index the best indicator of heat stress in lactating dairy cows in a subtropical environment? J. Dairy Sci. 92:109-116.

Eigenberg, R. A., T. M. Brown-Brandl, and J. A. Nienaber. 2010. Shade material evaluation using a cattle response model and meteorological instrumentation. Int. J. Biometeorol. 54:509-515.

Flamenbaum, I., D. Wolfenson, M. Mamen, and A. Berman. 1986. Cooling dairy cattle by a combination of sprinkling and forced ventilation and its implementation in the shelter system. J. Dairy Sci. 69:3140-3147.

Fregonesi, J. A., and J. D. Leaver. 2002. Influence of space allowance and milk yield level on behaviour, performance and health of dairy cows housed in strawyard and cubicle systems. Livest. Prod. Sci. 78:245-257.

Gaughan, J. B., S. Bonner, I. Loxton, T. L. Mader, A. Lisle, and R. Lawrence. 2010. Effect of shade on body temperature and performance of feedlot steers. J. Anim. Sci. 88:4056-4067.

Gebremedhin, K. G., H. Ni, and P. E. Hillman. 1997. Modeling temperature profile and heat flux through irradiated fur layer. Trans. ASAE 40:1441-1447.
Hahn, G. L. 1985. Management and housing of farm animals in hot environments. Pages 151-174 in Stress Physiology in Livestock. Vol. II, Ungulates. M. K. Yousef, ed. CRC Press, Boca Raton, FL.

Ittner, N. R., and C. F. Kelly. 1951. Cattle shades. J. Anim. Sci. 10:184-194.

Kelly, C. F., T. E. Bond, and N. R. Ittner. 1950. Thermal design of livestock shelters. Agric. Eng. 31:601-606.

Maloney, S. K., G. Moss, and D. Mitchell. 2005. Orientation to solar radiation in black wildebeest (Connochaetes gnou). J. Comp. Physiol. A Neuroethol. Sens. Neural. Behav. Physiol. 191:10651077.

Matzarakis, A., F. Rutz, and H. Mayer. 2010. Modelling radiation fluxes in simple and complex environments: Basics of the RayMan model. Int. J. Biometeorol. 54:131-139.

McGovern, R. R., and J. M. Bruce. 2000. A model of the thermal balance for cattle in hot conditions. J. Agric. Eng. Res. 77:81-92.

Metz, J. H. M., A. M. F. Mees, and P. Mekking. 1981. Space needed by cows for movement in loose-housing. Bedrijfsontwikkeling 12:905-910.

Monteith, J. L. 1980. Radiation balance. Pages 60-70 in Principles of Environmental Physics. Edward Arnold Publ., London, UK.

National Research Council. 2001. Nutrient Requirements of Dairy Cattle. 7th rev. ed. Natl. Acad. Sci., Washington, DC.

Porter, W. P., D. F. Parkhurst, and P. A. McClure. 1986. Critical radius of homeotherms. Am. J. Physiol. 250:R699-R707.

Ryan, D. P., M. P. Boland, E. Kopel, D. Armstrong, L. Munyakazi, R. A. Godke, and R. H. Ingraham. 1992. Evaluating two different evaporation cooling management systems for dairy cows in a hot, dry climate. J. Dairy Sci. 75:1052-1059.

SAS Institute. 1996. User's Guide: Statistics. Version 6. SAS Institute Inc., Cary, NC.

Schutz, K., A. Rogers, N. Cox, and C. Tucker. 2009. Dairy cows prefer shade that offers greater protection against solar radiation in summer: Shade use, behaviour, and body temperature. Appl. Anim. Behav. Sci. 116:28-34

Smith, T. R., A. Chapa, S. Willard, C. Herndon, R. J. Williams, J. Crouch, T. Riley, and D. Pogue. 2006. Evaporative tunnel cooling of dairy cows in the Southeast. I: Effect on body temperature and respiration rate. J. Dairy Sci. 89:3904-3914.

Walsberg, G. E., and B. O. Wolf. 1995. Effects of solar radiation and wind speed on metabolic heat production by two mammals with contrasting coat colours. J. Exp. Biol. 198:1499-1507.

Weaver, W. L., and R. N. Green. 1980. Simulation study of geometric shape factor approach to estimating earth emitted flux densities from wide field-of-view radiation measurements. Remote Sens. Environ. 9:265-276.

Webb, D. R., F. M. Knight, P. A. McClure, and W. P. Porter. 1986. Insulation of animals and birds-Function and ontogeny. Am. Zool. 26:A52.

Wiersma, F., and G. L. Nelson. 1967. Nonevaporative convective heat transfer from the surface of a bovine. Trans. ASAE 10:733-737. 